\title{
The effect of gamma rays on Afshari Ram semen motility in the plant diluent
}

\begin{abstract}
Today in our country transfer of Knowledge and technology complex and powerful peaceful uses of nuclear applications complex. The effect of medicinal plant extracts protect against gamma radiation and its harmful effects on human and animal models have been studied for more than 50years. Electromagnetic radiations such as gamma rays are indirectly ionizing radiation. Absorption of radiation during passage through matter, lose their kinetic energy and charged particles are produced. Gamma rays produce free radicals can be due to a break chemical bonds and the chain of events that biological changes such as mutations in membrane damage and initiate, therefore, in this study using panax ginseng the protection of sperm cells on in vitro condition. In this study four Afshari rams $(5 \pm 50 \mathrm{~kg}$ body weight and age 3 to 4 years), sperm was collected by electrical ejaculation. Then sperm was added to the Tris-based diluents plus this medical planet extract and they divided into seven groups and a control group and treated by radiation in seven doses. After gamma irradiation, sperm motility (progressive and total motility) was evaluated at zero time (immediately post ejaculation) and 24hours post ejaculation by CASA software. results in zero time showed that the progressive and total movement of sperm samples in low doses compared to the other dose groups had a significant increase $(\mathrm{p}<0.05)$ but gamma radiation in low-dose did not effect on the sperm motility on planet extender in high doses. There are some ingredients in panax ginseng medicinal plant extracts used in this study has been positive effect in industry fertility and reproduction in future.
\end{abstract}

Keywords: gamma-ray, ram semen, extender, panax-ginseng
Volume 2 Issue 6 - 2015

\author{
Saeed Safavi Pour,' Akbar Pirestani, ${ }^{2}$ Hadi \\ Fatolahi, ${ }^{3}$ Amir Shafiee Dastgerdi ${ }^{4}$ \\ 'Young Researchers and Elite Club, Islamic Azad University, Iran \\ ${ }^{2}$ Department of Animal Science, Islamic Azad University, Iran \\ ${ }^{3}$ Agricultural and Industrial Research school-Nuclear science \\ and technology, Research Institute of Iran, Iran \\ ${ }^{4}$ Department of Animal Science shahrekord, Iran
}

Correspondence: Saeed Safavi pour, Young Researchers and Elite Club, Isfahan (khorasgan)Branch, Islamic Azad University, Isfahan, Iran, Tel +98939215 98I2, Email damyar.info@gmail.com

Received: August 20, 2015 | Published: November 19,2015
Abbreviations: PM, percentage of progressive motility sperm; $\mathrm{TM}$, percentage of total motility sperm

\section{Introduction}

Ionizing radiations can cause mutations, infertility and even mortality in the exposed organisms and for this reason it has been applied for animal biological control. ${ }^{1}$ The choice of biological models with short physiological cycle, easy maintenance in laboratory and fast reaction to stimulation is relevant for the followup of experiments. Nuclear radioisotope accidents are potentially ecologically devastating due to their impact on marine organisms. Today, reproduction management as one of the most successful ways of raising sheep in the industry is that the subsequent effects on the income of farmers. To this end, different methods have been suggested to be one of the best methods for artificial insemination. ${ }^{2}$ Sperm have the least amount of non-chromosomal material to be damaged. Gamma rays create chromosomal deletions either small or large or chromosomal rearrangements such as translocations or inversions. In addition sperm mutagenesis is easy to do. Sperm can be mixed with a diluent appropriate for a long time even after the death of livestock kept and transferred to anywhere in the world. Diluents properties are not known to be seriously and any organization or institution to manually follow a specific pattern to it. Therefore, the commercial production of an appropriate and cost-effective diluent sheep is ready to refuse. Woon et al. ${ }^{3}$ on this topic confirmed that irradiation with gamma ray dose of 1 to $5.0 \mathrm{~Gy}$ of sperm and germ cells, the results are not destructive and can be useful. ${ }^{3}$ Lock \& Suarez ${ }^{4}$ with cobalt 60 gamma radiation on rat sperm did this as the doses of $150 \mathrm{~Gy}$ caused a significant increase in abnormal sperm. ${ }^{4}$ Safavi pour et al. ${ }^{5}$ shows that, panax ginseng and Silybum marianum extract medicinal plants in ram sperm diluent Afshari stated that the level of 3\% and 5\% extract, these planet extract the greatest impact on sperm motility. ${ }^{5}$

The aim of the present study was to evaluate the effect of gamma radiation on sperm diluent containing medicinal plant extracts and determine the most appropriate dose of gamma radiation on sperm diluent containing medicinal plant extracts (dosimetry).

\section{Materials and methods}

\section{Semen collection, evaluation and sample preparation}

Semen samples were collected from 4 mature Afshar rams (3 to 4years) maintained at the Animal Breeding Center Farm of Islamic Azad University, Branch of Isfahan (Khorasgan), Iran. The rams were feed $0.91 \mathrm{~kg}$ of concentrate daily and good quality hay and water were supplied ad libitum. After semen collection, the raw semen samples were transferred to the laboratory immediately, and kept in a water bath at $37^{\circ} \mathrm{C}$ for examination. Ejaculates were collected from the rams using the electrical ejaculator (imv, Frances) twice a week during the breeding season (autumn to early winter). Semen samples were mixed in a pool, balancing the sperm contribution of each ram to eliminate individual differences that containing a semen volume that varied between 1 and $2 \mathrm{ml}$, spermatozoa with $>70 \%$ progressive motility and concentrations higher than $2.5 \times 109$ spermatozoa $/ \mathrm{ml}$.

\section{Extender preparation}

Extender $(10 \mathrm{ml})$ was prepared in autoclaved double distilled water (prepared in Biotechnology Laboratory of Islamic Azad University of 
Khorasgan branch) containing $0.244 \mathrm{gm}$. TRIS, $0.136 \mathrm{gm}$. citric acid, $0.082 \mathrm{gm}$. D-fructose and $20 \% \mathrm{v} / \mathrm{v}$ egg yolk. ${ }^{6}$

\section{Extract preparation}

To accomplish this, we use the method of extraction by using Percolation (prepared in GOLDARU, Pharmaceutical Co)..$^{7}$ Then put the panax ginseng extract for 48 hours at 30 to $40^{\circ} \mathrm{C}$ and completely isolated environment free from microbes (oven). Then, the extracts were dried and then weighting using a sodium chloride serum injection $0.9 \%$ can hold volume after that the level of $3 \mathrm{mg}$ was added to the diluent.

\section{Irradiation}

Irradiated samples using body irradiation dosimetry laboratory V9 model made in America's secondary standard is performed. The device features spring maintenance $60 \mathrm{Co}$ with activity blindness 6000 , which is currently the source of the activity inside is about 1300 Curie. 1.17 and 1.33 electron volt energy sources, 60Co photons in each decay produces, on average, according to the share of each of the photon energy is equal, the average gamma energy emitted 1.25 electron volt be considered.

\section{A: treatment $+100 \mathrm{mGy}$ Gamma rays emitted \\ B: treatment $+200 \mathrm{mGy}$ Gamma rays emitted \\ C: treatment $+300 \mathrm{mGy}$ Gamma rays emitted \\ D: Treatment $+1,000 \mathrm{mGy}$ Gamma rays emitted \\ E: treatment $+150 \mathrm{mGy}$ Gamma rays emitted \\ F: treatment $+250 \mathrm{mGy}$ Gamma rays emitted \\ G: treatment $+500 \mathrm{mGy}$ Gamma rays emitted}

The extract contains levels of gamma control without radiation. Spermatozoa motility was evaluated using computer assisted semen analysis (CASA analyzer, video sperm test 2.1), an Olympus BX40 microscope under $100 \times$ magnifications and at $37^{\circ} \mathrm{C}$. Sperm motility was evaluated at zero time (immediately post ejaculation) and 24 hours post ejaculation by CASA software. The analysis of this study uses SPSS (VER.21, 2012) data software package, statistical model based on project ANNOVA were analyzed and compared between the mean and LS Means LSD test at 5\% significance level was used.

\section{Results and discussion}

The results of this study shows that 8 groups for exposure were considered separately after irradiation were evaluated by software Casa in the Figure 1, the results of it. On the whole, the experimental group D with $1,000 \mathrm{mg}$ dose Gary significantly in all experimental groups and the control group had $(\mathrm{P}<0.05)$, as well as in the experimental group $\mathrm{G}$ with a $500 \mathrm{mg}$ dose compared to the control group, only Gary meaningful $(\mathrm{P}<0.05)$ and the rest of the experimental group and the control group had no significant changes relative to each other. The progressive movement in Group D with $1,000 \mathrm{mg}$ dose compared to the control group decreased mobility Gary was statistically significant $(\mathrm{P}<0.05)$, but no significant changes were observed in the other experimental groups, with increasing dose gamma thinners environment with reduced sperm motility over time, the amount of activity in group A with $100 \mathrm{~mm}$ light gray against the $66 / 89 \%$ respectively (Figure 1). But after 24 hours and again repeated testing done on them, which according to the diagram (Figure 2) in the treatment of the experimental group $\mathrm{C}$ and $\mathrm{D}$ than in the control group had a significant reduction $(\mathrm{P}<0.05)$, and no significant changes compared to the other groups. In Group G (with a dose of 500mg Gray) compared to D group had a statistically significant increase $(\mathrm{P}<0.05)$ and compared to the control group, has been significantly reduced $(\mathrm{P}<0.05)$. The rest of the groups were significant changes. But the progressive experimental group C (300mg dose Gary), Group G (500mg Gary) and Group D (with a dose of 1,000mg Gary) compared to the control group showed a significant decrease $(\mathrm{P}<0.05)$ and nonsignificant changes in parameters of microscopic sperm, total gamma radiation dose by increasing the amount of sperm motility is reduced, but the group A (the dose of 100 Gary) to group F (Gary dose 250mg) of sperm motility is acceptable according to WHO standards (Figure 2). Xhi et al. ${ }^{8}$ reported that extracts of panax ginseng contain the following: oleic acids (fatty acids), more than 40 types of gin Sinozyd, more than ten kinds Panaksan (polysaccharides), water and fat-soluble vitamins. Simple sugars such as glucose or complex sugars such as polysaccharides, ${ }^{9}$ salicylate acid and Alkaline phosphatase in panax ginseng of its antioxidant properties and can be used for protection against premature aging of sperm and semen and sperm membrane integrity applied. ${ }^{10}$ Panax ginseng antioxidant effect by reducing free radicals, preventing oxidation and DNA damage in sperm globulin.

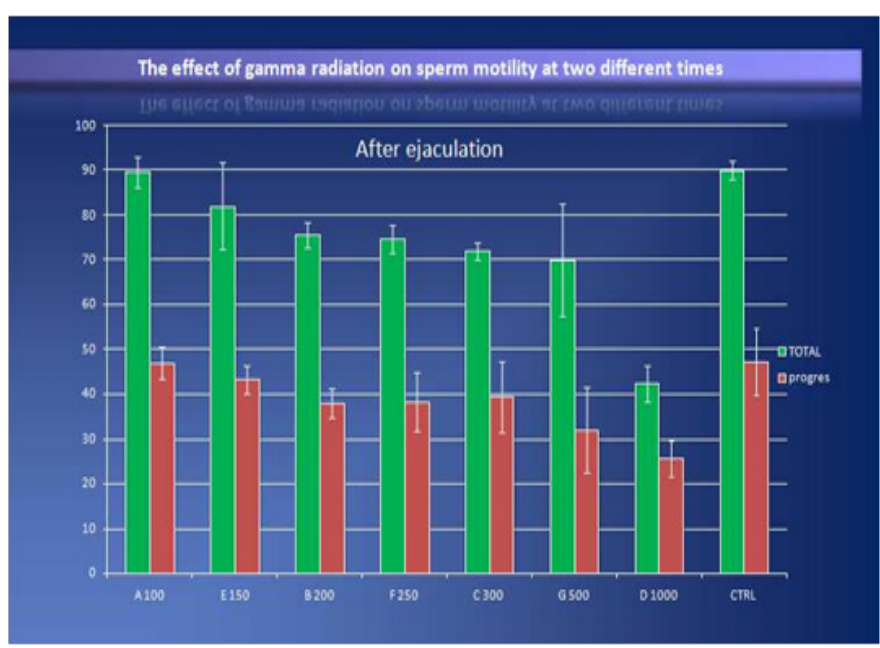

Figure I The effect of gamma radiation on sperm motility at two different times (after ejaculation).

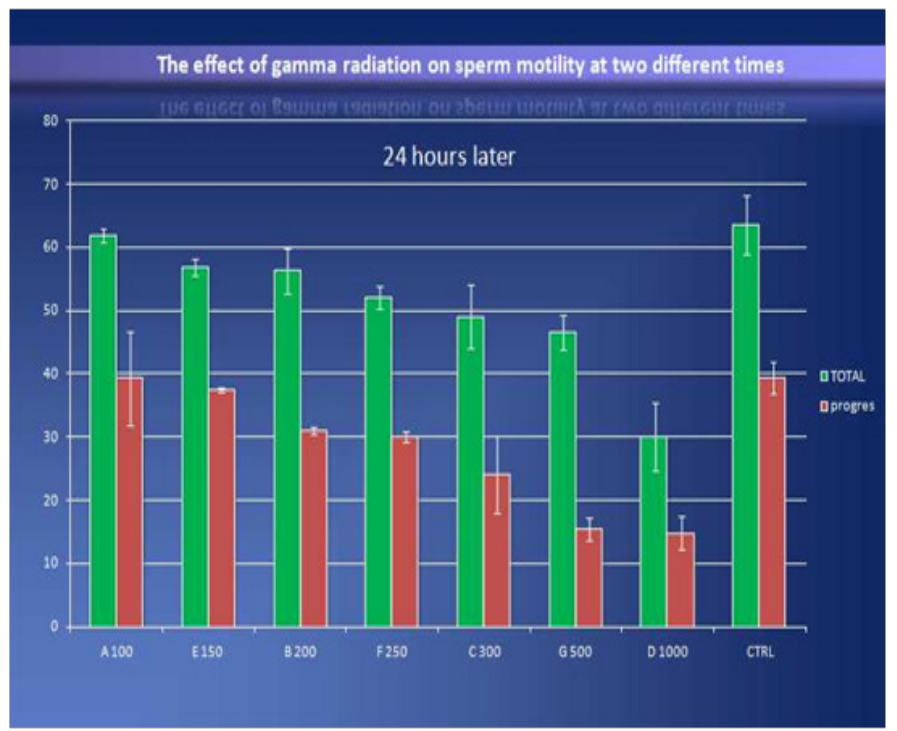

Figure $\mathbf{2}$ The effect of gamma radiation on sperm motility at two different times (24hours later). 
Koudelová \& Cook $^{11}$ showed that a dose of $175 \mathrm{~Gy}$ of gamma radiation can cause mutations in the sperm of patients is related to sex. Scientists reported that mice exposed to high doses of gamma radiation, the presence of abnormal sperm in the epididymis of mice increased. Exposure has adverse effects on sperm rams, and when panax ginseng extract used partly due to the effects of the protective effects of plant extracts reduced. Alkaline phosphatase also plays an important role in maintaining the cell membrane permeability. The radiation damages the cell membrane thus decline the alkaline phosphatase activity. The decrease in alkaline phosphatase activity may be due to the changes in the amino acid residues and catalytic activity of alkaline phosphatase, it has been reported that ginseng extract contains active components Baicalcein ginsenosides Rf and Baicalin ginsenosides Rbl and $\mathrm{Rg} 1$. These active components are well known to suppress radiation induced lipid peroxidation and reduce the radiation induced cellular damage. ${ }^{12,13}$

\section{Conclusion}

In conclusion, in this paper, According to the materials that exists in Ginseng, the results showed that the plant can be used in diluent and prevent the losses caused by irradiation. It can be a window to the science of fertility and infertility in animals.

\section{Acknowledgements}

None.

\section{Conflict of interest}

Author declares that there is no conflict of interest.

\section{References}

1. Bandekar JR, Chander R, Nerkar DP. Radiation control of vibrio parahaemolyticusin shrimp. Journal of Food Safety. 2007;8(2):83-88.
2. Adams NR. Permanent infertility in ewes exposed to plant oestrogens. Australian Veterinary journal. 1990;67(6):197-201.

3. Woon JH, Shin SC, Kang YM, et al. Sperm abnormalities in high- and low-dose-rate gamma-irradiated Korean dark-striped field mice. Radiation Protection Dosimetry Journal. 2011;146(3):280-282.

4. Lock F, Soares S. Increases in morphologically abnormal sperm in rats exposed to Co 60 irradiation. Environmental Mutagenesis journal. 2006;2(2):36-48.

5. Safavi Pour S, Pirestani A, Moattar F, et al. Protective effect of medicinal plant extracts panax ginseng and Silybum marianum in semen diluents irradiated by gamma rays. The first symposium in the field of research and treatment Embryology News. Isfahan: Royan. 2013.

6. Hafez ESE. Studies on the breeding season and reproduction of the ewe. Journal of Agricultural Science. 2005;42(3):189-265.

7. Aitken R. Motility Parameters and Fertility. Boca Raton: Control of Sperm Motility, Biological and Clinical Aspects. 1990:285-302p.

8. Xie JT, Mehendale SR, Wang A. American ginseng leaf: ginsenosid analysis and hypoglycemic activity. Pharmacol Res. 2004;49(2):113-117.

9. Buettner C, Yeh GY, Phillips RS. Systematic review of the effects of ginseng on cardiovascular risk factors. Ann Pharmacother. 2006;40(1):83-96.

10. Ng TB. Pharmacological activity of sanchi ginseng (Panax notoginseng). J Pharm Pharmacol. 2006;58(8):1007-1019.

11. Koudelová J, Cook P. Effect of Gamma Radiation and Sex-Linked Recessive Lethal Mutations on Sperm Transfer in Ephestia kuehniella (Lepidoptera: Pyralidae). The Florida Entomologist Journal. 2001;84(2):172-182.

12. Hwang SY, Kim WJ, Wee JJ, et al. Panax ginseng improves survival and sperm quality exposed to 2,3,7,8-tetrachlorodibenzo- p-dioxin. BJU Int. 2004;94(4):663-668.

13. Lynn KR, Skinner CJ. Radiolysis of an alkaline phosphatase. Radiat Res. 1974;57:358-363. 